\title{
DEVELOPMENT OF SELECTED MOTOR SKILLS IN BOYS AND GIRLS IN RELATION TO THEIR RATE OF MATURATION - A LONGITUDINAL STUDY
}

doi: 10.2478/v10038-012-0014-5

\section{BARTŁOMIEJ SOKOŁOWSKI *, MARIA CHRZANOWSKA}

University School of Physical Education, Kraków, Poland

\begin{abstract}
Purpose. The aim of this study was to examine the process of how motor skills were developed and shaped in boys and girls in relation to their rate of maturation, based on the use of peak height velocity (PHV), which measures biological maturity. Methods. This study made use of a longitudinal study researching the physical fitness of boys and girls from Kraków, Poland during the years 1980-1990. From the original sample population, 296 boys and 196 girls were selected for further analysis. Physical fitness tests were administered over the subsequent decade, measuring the following motor skills: speed, explosive strength of the lower limbs, static strength of the right and left hand, agility, dynamic strength of the abdominal muscles, static endurance of the upper limbs and shoulders, and flexibility. On the basis of the median and PHV age quartiles for both sexes, the examined individuals were divided into two cohorts: early maturers and late maturers. The mean values and standard deviations of the physical fitness test results were calculated based on biological age. Afterwards, the means and standard deviations of each tested motor skill of the early maturers were standardized into means and standard deviations of the late maturers. Results. The motor skills best performed in all age groups and in both sexes by early maturers were in tests of static strength of the hands. In the group of boys, early maturers in all age groups also performed the best in tests of speed and explosive strength of the lower limbs. Late-maturing girls were positively differentiated in each age group in tests of static strength of the upper limbs and shoulders, and in the dynamic strength of the abdominal muscles. Conclusions. The rate of maturation was found to significantly influence the results of fitness tests, particularly in the case of boys.
\end{abstract}

Key words: children and teenagers, longitudinal study, rate of maturation, peak height velocity (PHV), motor skills

\section{Introduction}

The development of motor skills in humans is a subject of on-going interest for both researchers and practitioners of physical education and sport. Tests used to determine various aspects of physical fitness focus on individual as well as collective motor skills. Of particular interest is the period of adolescent maturity due to the different rate and rhythm of how individual motor skills develop.

The development of motor skills has been studied in children and teenagers practicing sport [1-4] as well as how environmental [5, 6] and genetic [7] factors influence motor development. In addition, the results of studies have also been used to create a set of physical development norms [8,9]. Most conclusions were based on the use of cross-sectional [10-12] or longitudinal [13-18] studies, which used calendar age as a criterion of maturity. However, biological age is a more objective benchmark as in this case the influence of somatic development, providing more individual data as rate of maturation, is taken into account when performing various motor tasks. Frequently, biological maturity is determined by peak height velocity (PHV), or the maximum velocity in statural growth during adolescence.

\footnotetext{
* Corresponding author.
}

The use of PHV has been widely applied in practice as it allows for an individual look on the maturity process and its evaluation [8].

The aim of this study was to try to find out how the rate of maturation, based on peak height velocity (PHV), can influence motor skills, and particularly, how the development of speed, strength (static, dynamic and explosive), static endurance, flexibility and agility progresses in boys and girls. The issue in question is not novel, however, there are few studies which analyze this issue in a wider context by taking into consideration sex, age and a number of different motor skills at the same time, and, what is even more important, basing their research on longitudinal studies carried out on the same group of subjects.

\section{Material and methods}

Throughout 1980-1990 the University School of Physical Education in Kraków, Poland conducted an interdisciplinary, longitudinal study on adolescents. It included 820 students (460 boys and 360 girls) from schools in Mistrzejowice, a district in Kraków, Poland. The subjects were all urban schoolchildren and formed a relatively homogeneous population, taking into consideration their socio-economic and cultural background.

The study measured the children's physical characteristics, motor skills, mental growth and their ability 
to learn, with the results later presented in a few publications $[10,13,14]$. The motor skills tested in the study used a modified version of the International Physical Fitness Test, with the largest differences being that the static strength of both hands was examined (not only the dominant arm), long run was not performed, and the bent-arm hang was used instead of pull-ups for 12-year-old and older boys in order to test static endurance of the upper limbs and shoulders. Altogether, the modified physical fitness battery was used to assess speed (50 $\mathrm{m}$ dash), the explosive strength of the lower limbs (standing broad jump), the static strength of the right and left hand (measured by a hand dynamometer), running agility $(4 \times 10 \mathrm{~m}$ shuttle run), the dynamic strength of the abdominal muscles (by the number of sit-ups completed in $30 \mathrm{~s}$ ), the relative strength of the upper limbs and shoulders (bent-arm hang), and flexibility (sit-and-reach) throughout the subsequent years.

This study selected a sample size of 296 boys and 196 girls aged $8-16$ years based on the large sample size of these particular age groups as well as these pupils participating in all physical fitness tests. The age of peak height velocity was then determined based on the individual data for each of the studied children. The average age of maximal peak height velocity was then calculated, being 13.11 years for boys and 11.32 years for girls (Tab. 1). The obtained average age of PHV in boys and girls were found to be similar to the results published in other studies $[9,15,18-20]$.

On the basis of the values of the median and quartiles of PHV age for both sexes, the examined were then divided into two cohorts: early maturers and late maturers. Accordingly, early or late-maturing boys and girls constituted the I and IV distribution quartiles, respectively, with average maturers in the middle.

Table 1. Average PHV age of the sample population

\begin{tabular}{lccc}
\cline { 2 - 4 } & $N$ & Mean (yrs) & Standard deviation \\
\hline Boys & 296 & 13.11 & 1.24 \\
Girls & 196 & 11.32 & 1.18 \\
\hline
\end{tabular}

Table 2. Division of the sample population into three cohorts

\begin{tabular}{|c|c|c|c|c|}
\hline & Cohorts & $\begin{array}{c}\text { Early- } \\
\text { maturing }\end{array}$ & $\begin{array}{l}\text { Normal- } \\
\text { maturing }\end{array}$ & $\begin{array}{c}\text { Late- } \\
\text { maturing }\end{array}$ \\
\hline \multirow{3}{*}{ Boys } & Age (yrs) & $\begin{array}{c}\text { Less } \\
\text { than } 12.5\end{array}$ & $12.5-13.99$ & $\begin{array}{c}14.0 \\
\text { and more }\end{array}$ \\
\hline & Mean & 11.45 & 13.30 & 14.42 \\
\hline & $N$ & 74 & 148 & 74 \\
\hline \multirow{3}{*}{ Girls } & Age (yrs) & $\begin{array}{c}\text { Less } \\
\text { than } 10.5\end{array}$ & $10.5-12.5$ & $\begin{array}{c}12.6 \\
\text { and more }\end{array}$ \\
\hline & Mean & 9.69 & 11.31 & 12.69 \\
\hline & $N$ & 45 & 97 & 54 \\
\hline
\end{tabular}

The mean age and the numbers of subjects in each cohort are presented in Table 2 . The group of early maturers included boys who had their PHV before 12.5 years and the group of late maturers were those whose PHV occurred after 13.99 years. Girls who had PHV before the age of 10.5 years were recognized as early maturers and those with PHV after the age of 12.5 were considered late maturers.

Next, the mean values and standard deviations were calculated for the physical fitness test results among the biological age cohorts for boys (Tab. 3) and girls (Tab. 4), with the significance of differences was assessed with the Student's $t$-test. Subsequently, the means of each motor skill in the cohort of early maturers were standardized among the means and standard deviations of the late maturers.

\section{Results}

The differences in the obtained results between the cohorts are illustrated by profiles of the standardized differences for each of the examined motor skills. In order to better present the results, the negative and positive values of the standardized factors of the speed and agility tests were replaced (as a shorter completion time signified a better score).

In each of the studied calendar ages, the early-maturing boys ran the $50 \mathrm{~m}$ distance faster than the late maturers. Statistically significant differences appeared in the period from those who were 11 to 16 years old (the significance level was set at $p \leq 0.05$ ). The greatest differences were observed at the age of 14 and 15 years. In girls aged 8 to 13 years the results of the early maturers were better and a statistically significant difference is observed at the age of 11. Late-maturing girls presented better results at the ages of 14, 15 and 16 years (Fig. 1).

Early-maturing boys had better results in explosive strength of the lower limbs for each calendar age with significant differences found between the ages of 11-16 years. The girls did not present any consistent trends.

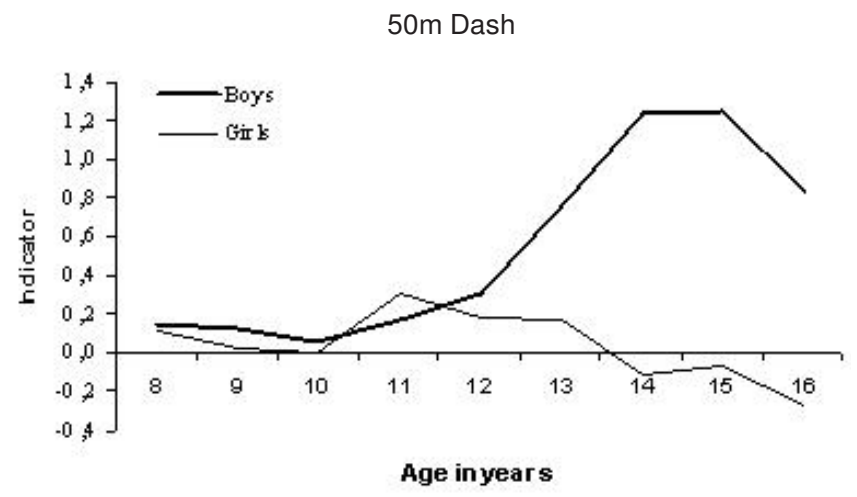

Figure 1. Profiles of standardized differences in the test of speed 


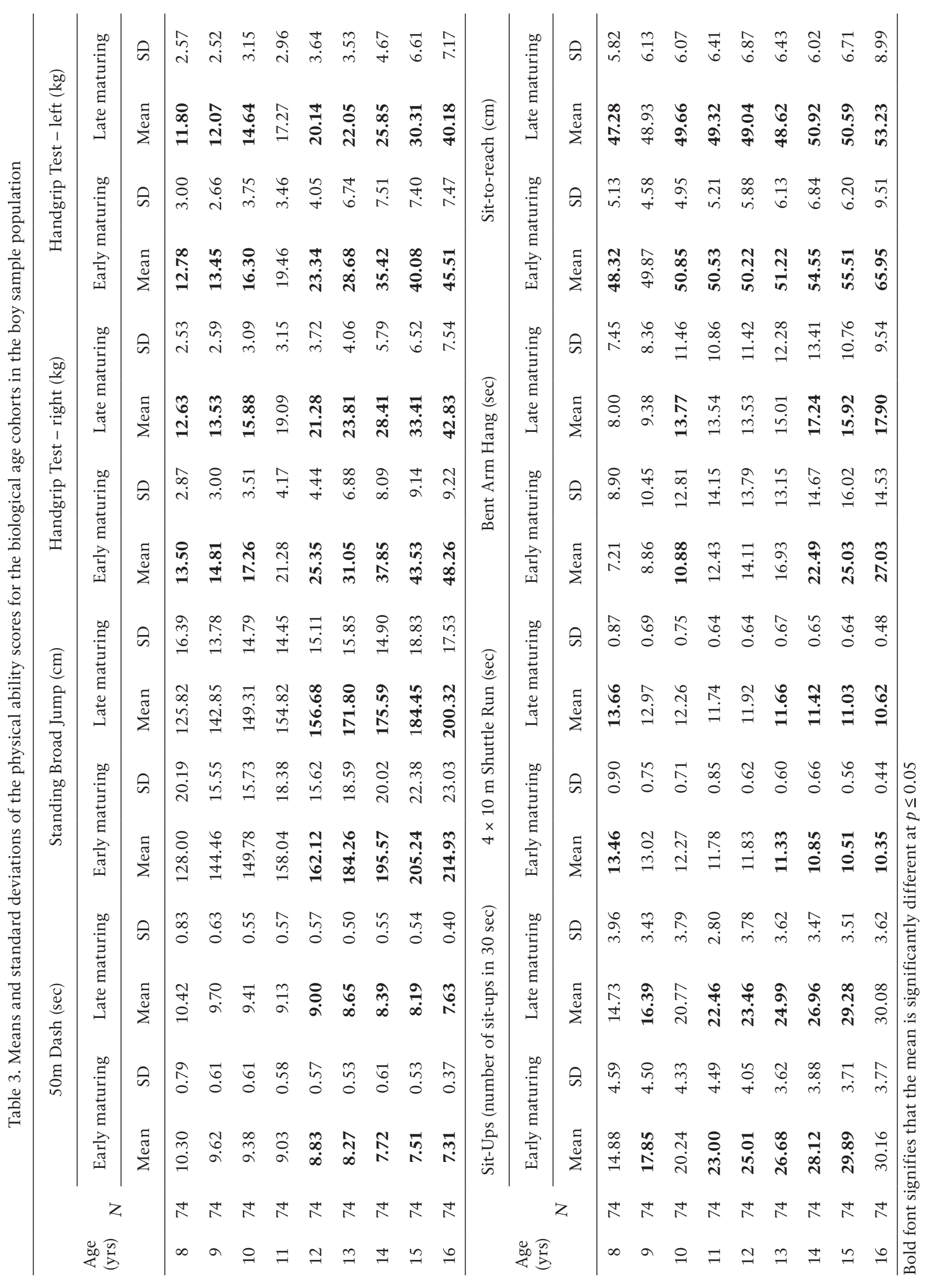




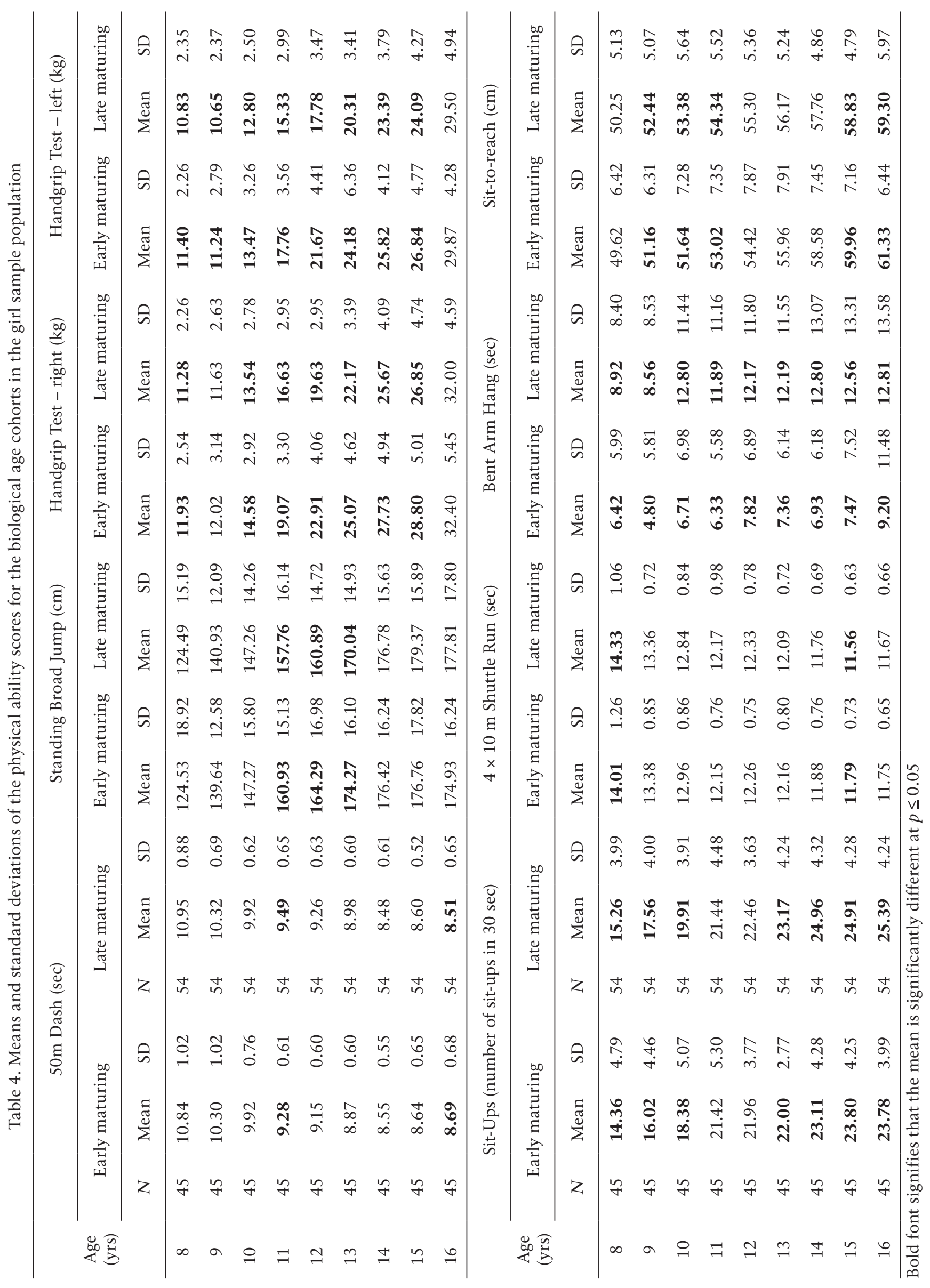




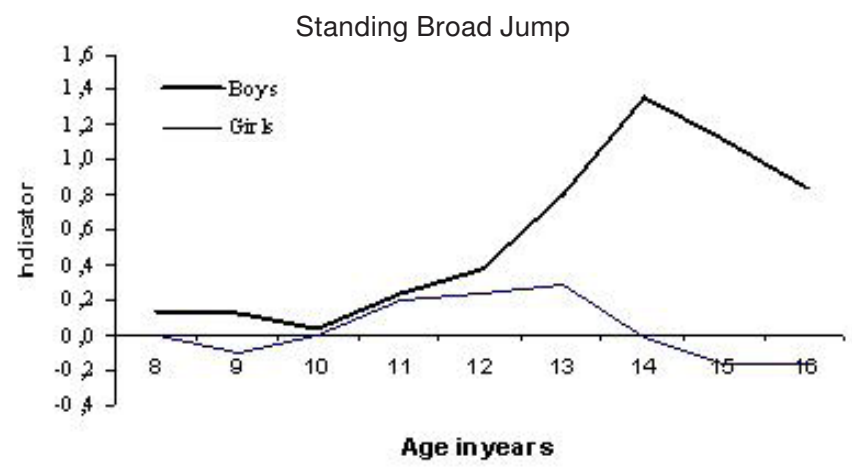

Figure 2. Profiles of standardized differences in the test of explosive strength of the lower limbs

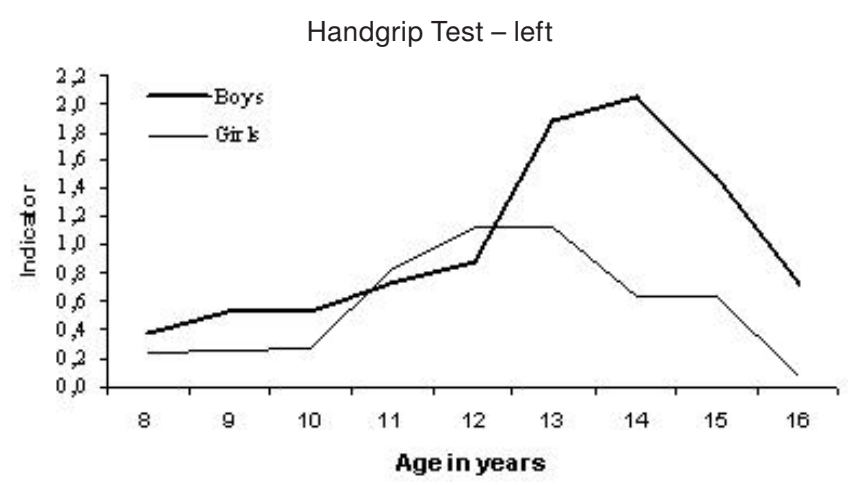

Figure 4. Profiles of standardized differences in the test of static strength of the left hand

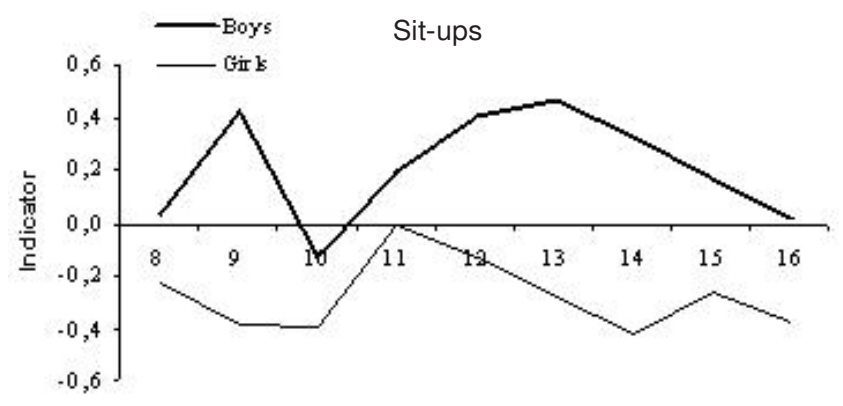

Age in years

Figure 6. Profiles of standardized differences in the test of dynamic strength of the abdominal muscles

At the age of 8,10 , and 14 there were no differences between the groups. At the age of 11, 12, and 13 years the early-maturing girls performed much better (Fig. 2).

The profiles illustrating the differences in strength measured by a hand dynamometer were found to be similar for both sexes, i.e., during the whole period under observation the early-maturing boys and girls performed better than the late maturers. The differences increased in the younger ages and in boys aged 12-14 years and in girls aged 12-13 years were the greatest. The differences became smaller in later years (Fig. 3, 4).

Early-maturing boys performed better in the shuttle run test when aged $8,12,13,14,15$ and 16 years, with the differences being statistically significant. The differentiation in girls was found to be a complex issue.

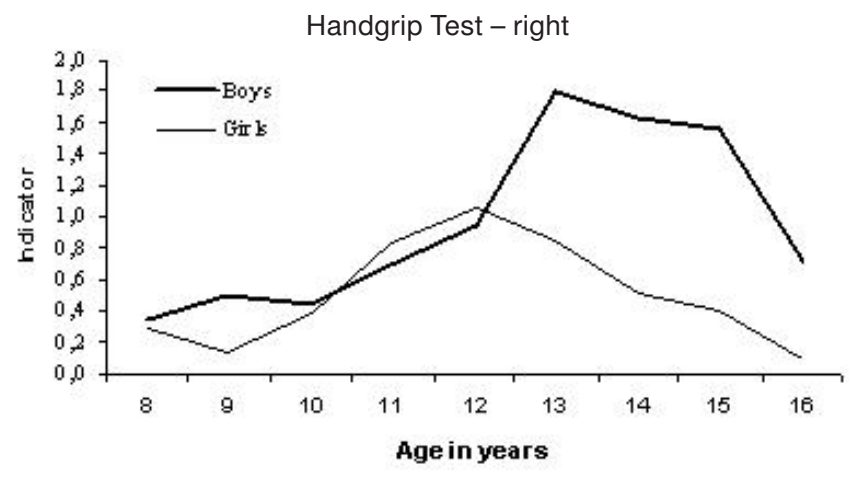

Figure 3. Profiles of standardized differences in the test of static strength of the right hand

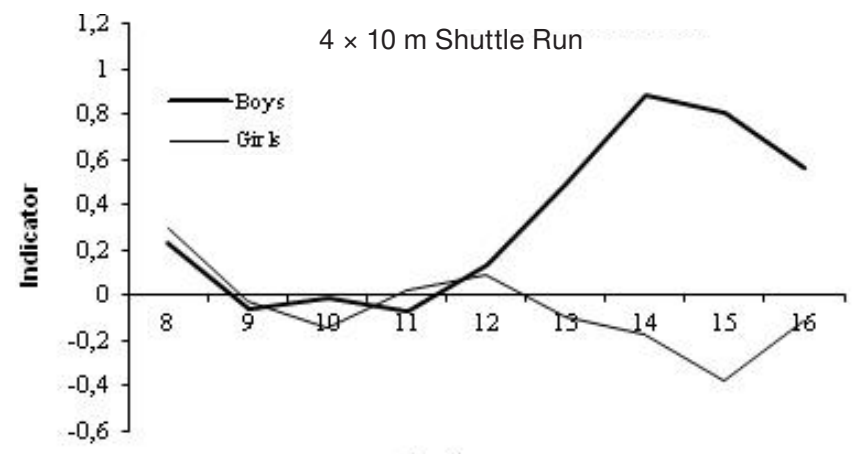

Age in years

Figure 5. Profiles of standardized differences in the test of agility

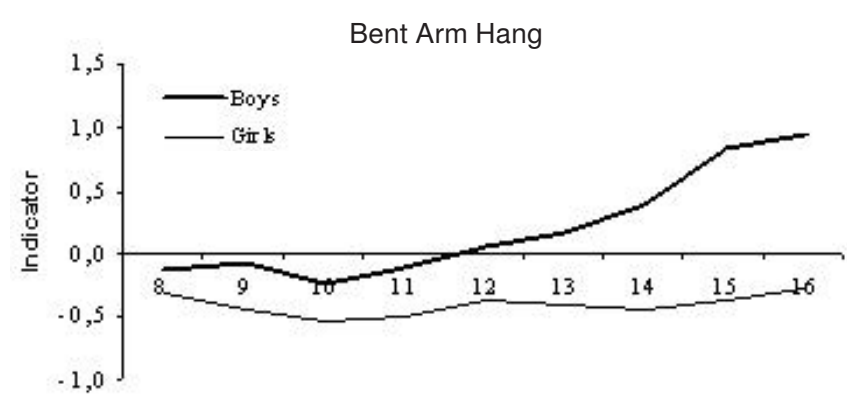

Age inyears

Figure 7. Profiles of standardized differences in the test of static endurance of the upper limbs and shoulders

Better results were obtained by the early-maturing girls aged 8, 11 and 12 years, but at the ages of 9,10 , and then from 13 to 16 years the cohort of the latematuring girls performed better (Fig. 5).

Profiles illustrating the differences in the number of sit-ups from a lying position were found to be different between the sexes. Early-maturing boys obtained better results (statistically significant) than late maturers. Only the ten-year-olds presented a slight difference favoring late-maturing boys. Girls presented a contrary relationship: better results were found in the cohort of late maturers. There was no significant difference at the age of 11 (Fig. 6).

In the bent-arm hang test, the late maturing boys obtained better results between 8 to 11 years, whereas 


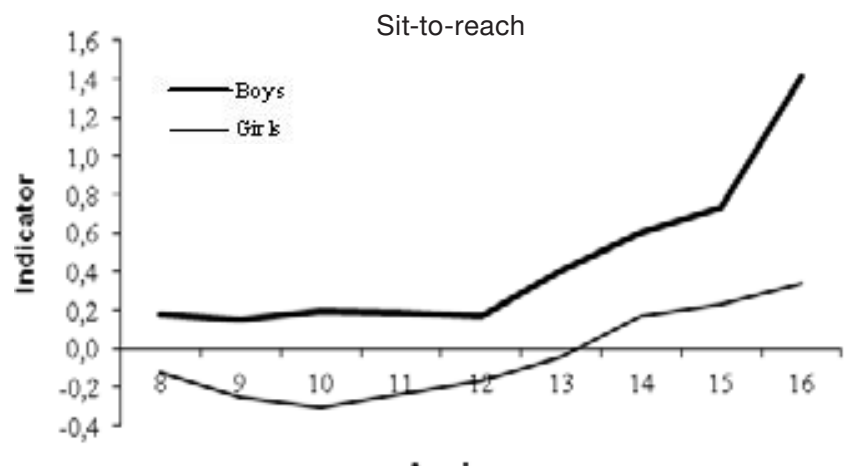

Age in years

Figure 8. Profiles of standardized differences in the test of flexibility

from 12 to 16 years the early maturers presented significantly better abilities. Completely different results were observed in girls: in all age groups the cohort of late maturers showed much better skill development (Fig. 7).

For the sit-to-reach test, higher flexibility was found in the cohort of early maturing boys for each calendar age. The greatest difference appeared at the age of 16 . Quite different profiles were noticed in girls at the age of $8,9,10,12$, and 13 years, where better results were obtained by the late maturing girls, while at the age of 14,15 , and 16 years early maturers performed better with significant differences found at the age of 15 and 16 (Fig. 8).

\section{Discussion}

There is no doubt that there is a connection between PHV and motor skills. Most studies found a stronger relationship in boys than in girls between developmental age and fitness [20-23]. This phenomenon was confirmed in the present study as the early maturing boys obtained better results in most tests, specifically in tests of speed, agility, static strength of the hands, explosive strength of the lower limbs, dynamic strength of the abdominal muscles and flexibility.

However, differences quickly grew with age. Only in case of static endurance of the upper limbs and shoulders at the age of $8-12$ years did the late maturers obtain better results. It is obvious that adolescents who mature earlier have taller statures than those who mature later, therefore any motor skills dependent on body height should be better developed in these individuals. A number of studies [11, 19, 21, 24, 25] confirm this fact, such as where tests of static strength indicate a rectilinear connection with body height or that taller individuals obtain better results in the standing broad jump. Body proportion, in this case having longer lower limbs, might be of crucial importance in the development of motor skills.

In the present study the biological age differentiated variously with the development of motor skills in girls. The early maturers were characterized by more endo- morphic and mesomorphic body types [12, 26, 27], which should affect their fitness levels. In the case of static strength of the hands, the observed differences favored the early maturers. In addition, in the speed tests the same cohort presented slightly better results. Tests of explosive strength of the lower limbs, agility and flexibility were found to not differentiate between the early- and late-maturing girls. Significant differences favoring the late maturers were observed in the test measuring the dynamic strength of the abdominal muscles, and particularly, in the tests of static endurance of the upper limbs and shoulders. This might result from a more leptosomatic body build of late-maturing girls. It can be assumed that body weight also is an important factor in these tests as they would be easier for lighter individuals.

However, while the rate of maturation and somatic features are important factors, Malina and Bouchard believe that they do not determine sports performance [28]. Early maturers achieve better results in motor tests as somatic development is grounded in strength and endurance development. These individuals are also taller and heavier and have higher body mass in relation to height, which is more advantageous in most motor tests when compared to normal- and late-maturing individuals. According to Łaska-Mierzejewska, early maturers achieve rather short-term success in children's competitions over late maturers and in those disciplines where body size counts [29]. However, they later frequently give up sport or are outpaced by their normal- or late-maturing peers who are characterized by thinner body builds, which is more advantageous in several sporting disciplines.

Data on sexual maturation and the ability to categorize pupils into groups of adolescent maturity may make it easier to recognize gifted future athletes. Following Łaska-Mierzejewska's juxtaposition [29], if a late maturer achieves excellent results in fitness tests when competing with similarly-aged peers, this may be used as a form of talent identification and indicate an individual's propensity towards sporting success. If an early maturer achieves better results among their peers, this rather may indicate only a temporary improvement in physical fitness and motor skills.

\section{Conclusions}

1. At a younger age the rate of somatic development does not affect motor development.

2 . The rate of maturation significantly influences the results of fitness tests and is particularly demonstrated in boys, who achieved better results in most of the analyzed motor skills.

3. The motor skills best performed in all age groups and in both sexes by early maturers were in tests of static strength of the hands. In the group of boys, early maturers in all age groups also performed the best in tests of speed and explosive strength of the lower limbs. 
4. The cohort of the late-maturing girls achieved better results in all age groups in tests of static strength of the upper limbs and shoulders, and of dynamic strength of the abdominal muscles.

\section{References}

1. Malina R.M., Rożek K., Ignasiak Z., Sławińska T., Fugiel J., Kochan K., Domaradzki J., Growth and functional characteristics of male athletes 11-15 years of age. Hum Mov, 2011, 12 (2), 180-187, doi: 10.2478/v10038011-0017-7.

2. Malina R.M., Ignasiak Z., Rożek K., Sławińska T., Domaradzki J., Fugiel J., Kochan K., Growth, maturity and functional characteristics of female athletes 11-15 years of age. Hum Mov, 2011, 12 (1), 31-40, doi: 10.2478/v10038011-0003-0.

3. Katić R., Retelj E., Milat S., Ivanisević S., Kudelj I., Development of motor and specific motor abilities for athletics in elementary school male and female first graders. Coll Antropol, 2008, 32 (4), 1141-1147.

4. Malina R.M., Physical growth and biological maturation of young athletes. Exerc Sport Sci Rev, 1994, 22, 389-433.

5. Puciato D., Morpho-functional development of children and adolescents from Jedlina-Zdrój with regard to objective quality of life of their families. Hum Mov, 2010, 11 (1), 66-70, doi: 10.2478/v10038-010-0005-3.

6. Mleczko E., Environmental differentiation vs. the level and dynamics of functional development in Krakow children aged 7-14 years [in Polish]. Antropomotoryka, 1993, 10, 57-114.

7. Bouchard C., Malina R.M., Perusse L., Defining performance, fitness, and health. In: Bouchard C., Malina R.M., Perusse L., Genetics of Fitness and Physical Performance. Human Kinetics, Leeds 1997, 89-98.

8. Gołąb S., Chrzanowska M., Sobiecki J., Żarów R., Kościuk T., Brudecki J. et al., The Child of Krakow 2000. Physical Fitness and body posture in the Krakow children and youth. [in Polish]. Studia i Monografie AWF w Krakowie, 2003, 22.

9. Tanner J.M., Davies P.S., Clinical longitudinal standards for height and height velocity for North American children. J Pediatr, 1985, 107 (3), 317-329, doi: 10.1016/ S0022-3476(85)80501-1.

10. Chrzanowska M., Gołąb S., Bocheńska Z., Panek S., The Krakow Child - the level of biological development of children and adolescents from the city of Krakow [in Polish]. AWF, Kraków 1988.

11. Jagiełło W., Kalina R.M., Tkaczuk W., Development of strength abilities in children and youth. Biol Sport, 2004, 21 (4), 351-368.

12. Loko J., Aule R., Sikkut T., Ereline J., Viru A., Motor performance status in 10 to 17-year-old Estonian girls. Scand JMedSciSports, 2000,10(2),109-113, doi:10.1034/j.16000838.2000.010002109.x.

13. Bocheńska Z., Morphofunctional and psychological development of school children from Nowa Huta of high physical fitness level as compared to groups of average and low fitness [in Polish]. AWF, Kraków 1987.

14. Panek S., Bocheńska Z., Chrzanowska M., Somatic, physiological and psychical development of children and adolescents of different level of physical fitness based on longitudinal studies [in Polish]. AWF, Kraków 1993, 103-113.
15. Juliano-Burns S., Mirwald R.L., Bailey D.A., Timing and magnitude of peak height velocity and peak tissue velocities for early, average, and late maturers boys and girls. Am J Hum Biol, 2001, 13 (1), 1-8, doi: 10.1002/15206300(200101/02)13:1<1::AID-AJHB1000>3.0.CO;2-S.

16. Kemper H., de Vente W., van Mechelen W., Twisk J.W., Adolescent motor skill and performance: Is physical activity in adolescence related to adult physical fitness? Am J Hum Biol, 2001, 13 (2), 180-189, doi: 10.1002/ 1520-6300(200102/03)13:2<180::AID-AJHB1027 $>3.0 . \mathrm{CO} ; 2-\mathrm{R}$.

17. Volver A., Viru A., Viru M., Formation of sprinting ability in girls. Acta Academiae Olimpiquae Estoniae, 2005, 13 (2), 11-15.

18. Żak S., Sterkowicz S., The influence of peak height velocity and age of girls on some of their co-ordination motor abilities. Kinesiology, 2004, 14, 45-54.

19. Sterkowicz S., Żak S., Development of strength in girls aged $8-15$ years in the aspect of peak height velocity [in Polish]. Ann UMCS, 2006, 60 (16), 222-226.

20. Yague P., De la Fuente J., Changes in height and motor performance relative to peak height velocity: a mixedlongitudinal study of Spanish boys and girls. Am J Hum Biol, 1998, 10 (5), 647-660, doi: 10.1002/(SICI)15206300(1998)10:5<647::AID-AJHB11>3.0.CO;2-8.

21. Branta C., Haubenstricker J., Seefeldt V., Age changes in motor skills during childhood and adolescence. Exerc Sport Sci Rev, 1984, 12 (1), 467-520.

22. Buenen G., Malina R., Growth and physical performance relative to the timing of the adolescent spurt. Exerc Sport Sci Rev, 1988, 16 (1), 503-540.

23. Szopa J., In the search of motor activity structure: a factor analysis of somatic and functional features as well as fitness tests in girls and boys aged 8-19 years [in Polish]. AWF, Kraków 1988.

24. Viru A., Loko J., Volver A., Laaneots L., Karelson K., Viru M., Age periods of accelerated improvement of muscle strength, power, speed and endurance in the age interval 6-18 years. Biol Sport, 1998, 15 (4), 211-227.

25. Raudsepp L., Jürimäe T., Relationships between somatic variables, physical activity, fitness and fundamental motor skills in prepubertal boys. Biol Sport, 1996, 13 (4), 279-289.

26. Chrzanowska M., Gołąb S., Żarów R., Sobiecki J., Matusik S., Trends in body adiposity and overweight and occurrence in children and youth in Krakow in the last thirty years [in Polish]. Pediatria Polska, 2002, 2, 113-120.

27. Volver A., Viru A., Viru M., Improvement of motor abilities in pubertal girls. J Sports Med Phys Fitness, 2000, 40 (1), 17-25.

28. Malina R.M., Bouchard C., Growth maturation and physical activity. Human Kinetics, Champaign 1991.

29. Łaska-Mierzejewska T., Anthropology in sport and physical education [in Polish]. COS, Warszawa 1999.

Paper received by the Editors: February 25, 2011

Paper accepted for publication: November 23, 2011

Correspondence address

Bartłomiej Sokołowski

ul. Śląska 5/6

30-003 Kraków, Poland

e-mail: b.j.sokolowski@interia.pl 